\title{
Characterization and influence of hydrocolloids on low caloric orange jellies
}

\author{
Michelle Barbosa Lima1', Flávia Mappa Domingos², Jerusa Josiane Francisca de Jesus Lima², \\ Reginaldo de Souza Monteiro', Orlando David Henrique dos Santos ${ }^{3}$, Patrícia Aparecida Pimenta Pereira ${ }^{2 *}$ \\ ${ }^{1}$ Master Program in Health and Nutrition, Federal University of Ouro Preto, Ouro Preto, MG, Brazil, ${ }^{2}$ Department of Food, Federal University of \\ Ouro Preto, Ouro Preto, MG, Brazil, ${ }^{3}$ Department of Pharmacy, Federal University of Ouro Preto, Ouro Preto, MG, Brazil
}

\section{A B S T R A C T}

\begin{abstract}
The aim of this study was to evaluate the influence of hydrocolloids (low methoxyl pectin [LMP], guar gum, and carrageenan) on the characteristics of low caloric orange jellies. A mixture design with to 12 tests to determine properties of the jellies. Physical, physicochemical, and sensory analyses were performed. The results were analyzed by response surface methodology and a Tukey mean test at a significance level of $5 \%(p \leq 0.05)$. The formulations with high LMP concentration resulted in low caloric orange jellies that have a rigid structure, light color, more acidic nature and exhibited optimal sensory acceptability. The jelly formulations with carrageenan concentration of $0.25 \%$ had lower total sugar values. Therefore, for the preparation of low caloric orange jellies, it is necessary to use LMP concentration between $0.75 \%$ and $1 \%$ and carrageenan concentration of $0 \%-0.25 \%$ as well as to exclude guar gum.
\end{abstract}

Keywords: Kappa-carrageenan; Guar gum; Low methoxyl pectin; Simplex-lattice

\section{INTRODUCTION}

Oranges are among the most consumed fruits in the world on a large scale because of their pleasant flavor and high nutritional value. Orange juice contains a high concentration of vitamin $\mathrm{C}$ and appreciable amounts of other essential nutrients, such as carotenoids, folate, and potassium. Moreover, it is a source of flavonoids, hesperidin, and naringenin, which are provide protection against cancer and atherosclerosis (Jayaprakasha et al., 2008).

In recent decades, consumers have noticed that a healthy diet is one way to maintain good health. The demand for foods with low calories and saturated fat as well the demand by consumers for products with high-quality ingredients reveals the necessity of using technologies that provide microbiological security and increase their commercial validity (Chow, 2000; Hoffman, 2008).

Considering that jellies are an important alternative for processing, utilization, and consumption of fruits, fruit jellies represent the object of a market that is growing due to the sensory acceptability and high-value-added and nutritional quality (Ferreira et al., 2011; Oliveira et al., 2016; Korus et al., 2017).

Conventional jellies are obtained using high methoxyl pectins (HMPs), which constitute firm and stable gels in environments having above $55 \%$ soluble solid concentration and $2.8-3.5 \mathrm{pH}$. A higher $\mathrm{pH}$ results in soft gels; for lower $\mathrm{pH}$ (up to 2.0), the gels are very hard; and for extremely low $\mathrm{pH}$ (below 2.0), the pectin becomes hydrolyzed. Already, low methoxyl pectins (LMPs) may form stable gels in the absence of sugars but require the presence of bivalent ions, such calcium, which provoke the formation of crossed links between molecules. This type of gel is more appropriate for products with a reduction/ exclusion of sugar. LMP is less sensitive to $\mathrm{pH}$ than HMP, allowing the production of gels in the $\mathrm{pH}$ range from 2.5 to 6.5. Although this pectin does not require the addition of sugar to make the gel, as HMP, the addition of 10 to $20 \mathrm{~g}$ of saccharose per $100 \mathrm{~g}$ of products results in a gel with a more appropriate texture (Zambiazi et al., 2006).

The use of LMPs and sugar substitutes in the preparation of low-calorie products causes changes in the formation

\footnotetext{
*Corresponding author:

Patrícia Aparecida Pimenta Pereira, Department of Food, Federal University of Ouro Preto, Ouro Preto, MG, Brazil.

E-mail: patriciaaparecidapimentapereira@yahoo.com.br

Received: 21 May 2018; $\quad$ Accepted: 19 December 2018
} 
of the pectin gel and in the conditions under which the products are obtained; however, when not used properly, LMPs and sugars can cause product fragility or further syneresis (Campos and Cândido, 1995; Gajar and Badrie, 2001).

Hydrocolloids are included in the preparation of low caloric jellies to improve and maintain rheological characteristics, such as texture, viscosity, and structure, which are important to impart flavor of the product. Hydrocolloids typically withhold water and increase viscosity and gelation (Dziezak, 1991).

Considering the characteristics of the jellies and their preparation methods, many researchers have demonstrated the advantages of using combined hydrocolloids (Dunstan et al., 2001; Ramírez et al., 2002; Mandala et al., 2004; Arda et al., 2009; Pereira et al., 2017).

Thus, the objective of this study was to evaluate the influence of hydrocolloids on the characteristics of low caloric orange jellies.

\section{MATERIALS AND METHODS}

\section{Processing of low caloric orange jellies}

Ripe oranges (Pera Rio cultivar) were used from a local market. The guavas were processed in the Sensory Analysis Laboratory in the Department of Food at the Federal University of Ouro Preto/MG, Brazil. The fruits were washed with water, sanitized in a $200 \mathrm{mg} \mathrm{L}^{-1}$ sodium hypochlorite solution for $15 \mathrm{~min}$, selected, pulped in an electrical squeezer, packed in low-density polyethylene bags, and frozen at $18{ }^{\circ} \mathrm{C}$. The following ingredients were used: sucrose (Alvinho Governador Valadares, Brazil), sucralose, acesulfame-k, polydextrose (Nutramax Catanduva, Brazil), potassium sorbate, LMP (Rica Nata Piracema, Brazil), guar gum (PrymeFoods Sorocaba, Brazil), and $x$-carrageenan (Gastronomy Lab Distrito Federal, Brazil).

The different formulations of low caloric orange jellies were processed in open stainless-steel pots by modifying the methodology proposed by Souza et al. (2012). The mixture of orange juice $(60 \%)$, sucrose $(20 \%)$, and polidextrose $(18.925 \%)$ was heated to achieve a $30^{\circ}$ Brix concentration. The hydrocolloids (LMP, guar gum, and carrageenan gum) were dissolved in $5 \mathrm{~mL}$ of water and immediately added to the mixture, according to the experimental design (Table 1), containing 1\% of gelling agents. The total quantity of hydrocolloids was defined by the previous tests. The process of cooking continued until a total soluble solid content of $60^{\circ}$ Brix was obtained. Sweeteners were added according to Souza et al. (2013) ( $0.01875 \%$ of acesulfame-k and $0.00625 \%$ of sucralose).
Potassium sorbate $(0.05 \%)$ was added at the end of the cooking process (diluted 1:1 in water at room temperature) to prevent degradation at a high temperature (above $85^{\circ} \mathrm{C}$ ). Low caloric orange jellies were placed in glass jars after being previously sterilized and filling was performed at a high temperature $\left(85^{\circ} \mathrm{C}\right)$. The containers were closed, cooled to room temperature, and stored in an incubator chamber at $25^{\circ} \mathrm{C}$ for further analysis.

\section{Rheological measurements}

The rheological measurements were performed in a cone/ plate-type rheometer (Brookfield model RV-III) connected to the Rheocalc software Version V.3.0 using a spindle CP52 and $0.5 \mathrm{~g}$ of sample at $25^{\circ} \mathrm{C}$. The measurements were performed from 1 to $250 \mathrm{rpm}$ by increasing the speed by $50 \mathrm{rpm}$ after every 10 min obtain an upward curve. The procedure was repeated in the opposite manner by progressively reducing the speed (250 to $1 \mathrm{rpm}$ ) to obtain a downward curve. The measurements were performed in two replicates. Experimental data for the flow curves were adjusted using the power law model. The parameters included consistency index (K, Pa. $\left.\mathrm{s}^{\mathrm{n}}\right)$ and flow index (n, dimensionless).

\section{Physicochemical analysis}

A physicochemical analysis (color, titratable acidity, moisture, and total sugar) of low caloric orange jellies was performed in triplicate.

To evaluate the color, a spectrophotometer was used (Musell, Hunter, CIE, CIELAB). The color space was set in the rectangular coordinates ( $\mathrm{L}^{*}, \mathrm{a}^{*}$ and $\left.\mathrm{b}^{*}\right)$. The color of the jellies was determined according to the methodology proposed by Lau et al. (2000). The values of L*, a* and b* were determined using a colorimeter (Minolta CR model unit 400) by employing D65 (daylight) and the standard CIELab, where L* ranges from 0 (black) to 100 (white), $\mathrm{a}^{*}$ varies from green $(-)$ to red $(+)$, and $\mathrm{b}^{*}$ ranges from blue $(-)$ to yellow $(+)$.

The values of total acidity (IAL, 2008) and moisture (AOAC, 2005) were determined.

The method proposed by Dische (1962) was used for the determination of total sugar.

\section{Sensory evaluation}

An acceptance test in relation to color, flavor, consistency, sweetness, and overall liking was conducted in the laboratory with 100 consumers evaluating the low caloric orange jellies using a 9-point hedonic scale, where $1=$ extremely dislike and $9=$ extremely like (Stone and Sidel, 1993).

The sensory analysis was performed with the approval of the local ethics committee (approval number 32888814.6.0000.5150).

Emir. J. Food Agric • Vol $31 \bullet$ Issue $1 \bullet 2019$ 
The sensory evaluation was conducted in three sessions (four samples per session) in individual booths. During the sensory analysis, the samples were maintained at $20^{\circ} \mathrm{C}$. The samples (approximately $5 \mathrm{~g}$ of each) were served in disposable plastic cups and coded using three-digit numbers obtained from a table of random numbers (Acosta et al., 2008).

\section{Experimental design and statistical analysis}

In this study, a simplex-lattice mixture design (Cornell, 1983) was used to determine and optimize the concentrations of LMP (X1), guar gum (X2), and carrageenan gum (X3) in the low caloric orange jellies on the basis of their rheological, physicochemical, and sensory analyses. The design and experimental levels for the three factors are presented in Table 1.

Statistical analyses were based on the predicted model. The general model of the regression function was adjusted to

\section{Table 1: Independent variables of mixed Jelly samples} according to the simplex-lattice mixture design

\begin{tabular}{lccc}
\hline Formulations & \multicolumn{3}{c}{ Variables } \\
\cline { 2 - 4 } & $\mathbf{X}_{1}$ & $\mathbf{X}_{2}$ & $\mathbf{X}_{3}$ \\
\hline F1 & 1 & 0 & 0 \\
F2 & 0 & 1 & 0 \\
F3 & 0 & 0 & 1 \\
F4 & 0.5 & 0.5 & 0 \\
F5 & 0.5 & 0 & 0.5 \\
F6 & 0 & 0.5 & 0.5 \\
F7 & 0.68 & 0.16 & 0.16 \\
F8 & 0.16 & 0.68 & 0.16 \\
F9 & 0.16 & 0.16 & 0.68 \\
F10 & 0.33 & 0.33 & 0.34 \\
F11 & 0.33 & 0.33 & 0.34 \\
F12 & 0.33 & 0.33 & 0.34 \\
\hline X:
\end{tabular}

$\mathrm{X}_{1}$ : low methoxyl pectin (LMP), $\mathrm{X}_{2}$ : guar gum, $\mathrm{X}_{3}$ : carrageenan gum.

$\begin{aligned} & \text { Table 2: Values of flow index and consistency index of mixed } \\
& \text { low caloric orange Jellies }\end{aligned}$
\begin{tabular}{lcc}
\hline Formulations & $\mathbf{n}$ & $\mathbf{K}\left(\mathrm{Pa} . \mathbf{s}^{\mathrm{n}}\right)$ \\
\hline F1 & 0.30 & 78.712 \\
F2 & 0.60 & 4.037 \\
F3 & 0.34 & 34.856 \\
F4 & 0.56 & 5.201 \\
F5 & 0.33 & 40.565 \\
F6 & 0.42 & 21.074 \\
F7 & 0.55 & 7.525 \\
F8 & 0.59 & 9.877 \\
F9 & 0.24 & 55.344 \\
F10 & 0.44 & 37.968 \\
\hline
\end{tabular}

*Formulation 10: mean of rheological values obtained by formulations 10 , 11 and 12. the values of the variable answers. Those values have linear and non-linear terms according to Equation 1.

$Y_{1}=B_{1} X_{1}+B_{2} X_{2}+B_{3} X_{3}+B_{12} X_{1} X_{2}+B_{13} X_{1} X_{3}+B_{23} X_{2} X_{3}$

To evaluate the data adjustment, the analysis of variance (ANOVA) and the coefficient of determination $\left(\mathrm{R}^{2}\right)$ for each parameter were determined and analyzed by the Statistica 8.0 software package (StatSoft Inc., USA). For the parameters in which there was no adjustment of the model, the Scott-Knott mean test was used to verify if there was a difference between samples at a significance level of $5 \%$ ( $\mathrm{p} \leq 0.05)$ by using the Sisvar software (Ferreira, 2000).

\section{RESULTS AND DISCUSSION}

\section{Rheological measurements}

The rheological measurements of the formulations were evaluated using the power law model, and the relative parameters from the model are presented in the Table 2. All formulations presented a flow index (n) of less than one, which means that they have pseudoplastic behavior once the fluids are static and present a disorderly state; when subjected to shear stress, the molecules tend to be guided into the direction of the applied force. Higher the tension applied better is the structural order. Therefore, the apparent viscosity will be less (Holdsworth, 1971).

Steffe (1996) reported that when the consistency index $(K)$ is higher than zero and when the flow index is $0<\mathrm{n}<1$, the fluid is considered to be non-Newtonian and pseudoplastic. The pseudoplastic behavior is frequently reported in formulations that contain natural, synthetic, or polymer gums (Yasar et al., 2007), which corroborates with the present study.

For the consistency index (Table 3), there was a positive significance effect ( $\mathrm{p} \leq 0.05)$ in X1 (LMP), X3 (carrageenan) and between X2X3 (guar gum and carrageenan) as well as a negative significance effect ( $\mathrm{p} \leq 0.05$ ) between $\mathrm{X} 1 \mathrm{X} 2$ (LMP and guar gum). For the flow index (Table 3), there was a positive significance effect $(\mathrm{p} \leq 0.05)$ between X1X2 (LMP and guar gum) and X1X3 (LMP and carrageenan).

Therefore, the jellies that presented a higher consistency index (Figure 1a) included those that were obtained with LMP concentrations above $0.75 \%$ combined with those

Table 3: Predicted model for the consistency index and flow index of mixed low caloric orange Jellies

\begin{tabular}{lrr}
\hline Parameter & Predicted model & $R^{2}$ \\
\hline $\mathrm{K}\left(\mathrm{Pa} . \mathrm{s}^{\mathrm{n}}\right)$ & $35832.0 \mathrm{X}_{1}{ }^{*}+4029.0 \mathrm{X}_{2}+25964.4 \mathrm{X}_{3}{ }^{*}-84336.2 \mathrm{X}_{1} \mathrm{X}_{2}{ }^{*}-43021.0 \mathrm{X}_{1} \mathrm{X}_{3}+99381.4 \mathrm{X}_{2} \mathrm{X}_{3}{ }^{*}$ & 0.85 \\
$\mathrm{n}$ & $8.4667 \mathrm{X}_{1}{ }^{*}+0.7298 \mathrm{X}_{2}+0.4201 \mathrm{X}_{3}-15.8869 \mathrm{X}_{1} \mathrm{X}_{2}{ }^{*}-16.2941 \mathrm{X}_{1} \mathrm{X}_{3}{ }^{*}+2.8066 \mathrm{X}_{2} \mathrm{X}_{3}$ & 0.91 \\
\hline $\mathrm{X}_{1}$ : low methoxyl pectin (LMP), $\mathrm{X}_{2}:$ guar gum, $\mathrm{X}_{3}$ : carrageenan gum. ${ }^{*}$ Significance to level of 0.05. &
\end{tabular}


with guar gum concentration $0 \%-0.75 \%$ and carrageenan concentration $0.25 \%-1 \%$. Thus, the use of gelling agents (LMP, guar gum, and carrageenan) influenced the consistency index values. In addition, the combination of guar gum and carrageenan tended to increase the index values.

According to Cui (2005), there is synergetic increase in the viscosity or resistance of the gel due to the mixture of the galactomannan (guar gum) with some types of polysaccharides, such as xanthan, carrageenan-k, and agarose. This corroborates with the results obtained in this study.

In the case of LMP, the increase in the consistency index may have occurred due to the presence of calcium in the orange pulp, which contains between 7 and $11 \mathrm{mg}$ of calcium per $100 \mathrm{~g}$ of the edible part of the fruit (USDA, 2005). This index occurs because the LMP molecules interact with the calcium ions in the juice; therefore, gel formation was ensured by the ionic bonds formed by the bivalent metallic ions in which calcium (Fennema et al., 2010) had the most pronounced effect on high concentrations of LMP, resulting in an increase in the consistency index.

Regarding the carrageenan, in Pietrasik (2003) in which the binding and texture properties of gels of processed meats was studied with carrageenan, egg albumin, and microbial transglutaminase, it was determined that samples of meat products prepared with carrageenan had a substantial increase in hardness.

At temperatures above $60^{\circ} \mathrm{C}$, carrageenans exist as random (disordered) ball structures because of the electrostatic repulsions between the polymer chains. Once cooled, the polymeric chains change conformation to a helix structure (ordered). Additional cooling and the presence of cations $\left(\mathrm{K}^{+}, \mathrm{Ca}^{+2}\right.$, and $\left.\mathrm{Na}^{+}\right)$lead to the aggregation of helixes and formation of a stable gel forming by intermolecular interactions between carrageenan chains (Rhein-Knudsen et al., 2015; Tavassoli-Kafrani et al., 2016). As carrageenan interacted with the calcium ions of the orange pulp in this study, there was an increase in the consistency index.

We observed largest values for the flow index (Figure 1b) in regions with concentrations above $0.75 \%$ of LMP, and the lowest values were in the regions that have between 0 and $0.75 \%$ of LMP and $0.25 \%$ and $1 \%$ of guar gum or between 0 and $0.75 \%$ of LMP and $0.25 \%$ and $1 \%$ of carrageenan.

According to the contour plot (Figure 1b) with increased LMP concentration, a reduction in the pseudoplasticity of the jellies occurred. Nevertheless, because the values were $\mathrm{n}<1$ for all jelly formulations, it was concluded that all formulations exhibited pseudoplastic behavior.

\section{Physicochemical analysis}

For the lightness $\left(\mathrm{L}^{*}\right)$ (Table 4$)$, there was positive significant effect $(\mathrm{p} \leq 0.05)$ in X1 (LMP), X2 (guar gum), and X3 (carrageenan) and between X1 and X2 (LMP and guar gum) because these effects were similar (similar coefficients). According to the contour plot (Figure 2), regions with a combination between $0.25 \%$ to $0.75 \%$ of LMP and $0.25 \%$ to $0.75 \%$ of guar gum presented the largest values for this parameter (clearer jellies). Contrary results (darker jellies) were obtained for regions that tended toward $1 \%$ of only one of the gelling agents.

In the study of processing and physicochemical characterization of the diet jellies of umbu-caja during storage under ambient conditions and using different LMP concentrations $(0.5 \%, 1 \%, 1.5 \%)$ as the gelling agent, Oliveira et al. (2014) observed that all formulations

Table 4: Predicted model for the lightness $\left(L^{*}\right)$ of mixed low caloric orange Jellies

\begin{tabular}{lcc}
\hline Parameter & Predicted model & $\mathbf{R}^{2}$ \\
\hline $\mathrm{L}^{*}$ & $30.84 \mathrm{X}_{1}{ }^{* *}+29.90 \mathrm{X}_{2}{ }^{* *}+29.09 \mathrm{X}_{3}{ }^{* *}+$ & 0.72 \\
$31.44 \mathrm{X}_{1} \mathrm{X}_{2}{ }^{* *}-5.31 \mathrm{X}_{1} \mathrm{X}_{3}-0.02 \mathrm{X}_{2} \mathrm{X}_{3}$ & \\
\hline \multicolumn{2}{l}{$\mathrm{X}_{1}$ : low methoxyl pectin (LMP), $\mathrm{X}_{2}$ : guar gum, $\mathrm{X}_{3}$ : carrageenan gum. } \\
** Significance to level of 0.05.
\end{tabular}

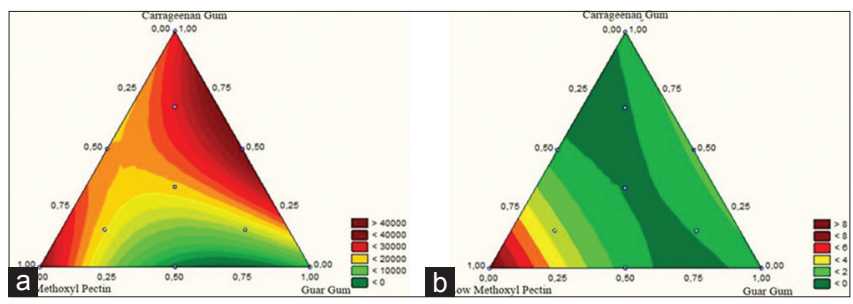

Fig 1. Contour Plot to the Consistency Index (a) and Flow Index (b) of Mixed Low Caloric Orange Jellies.

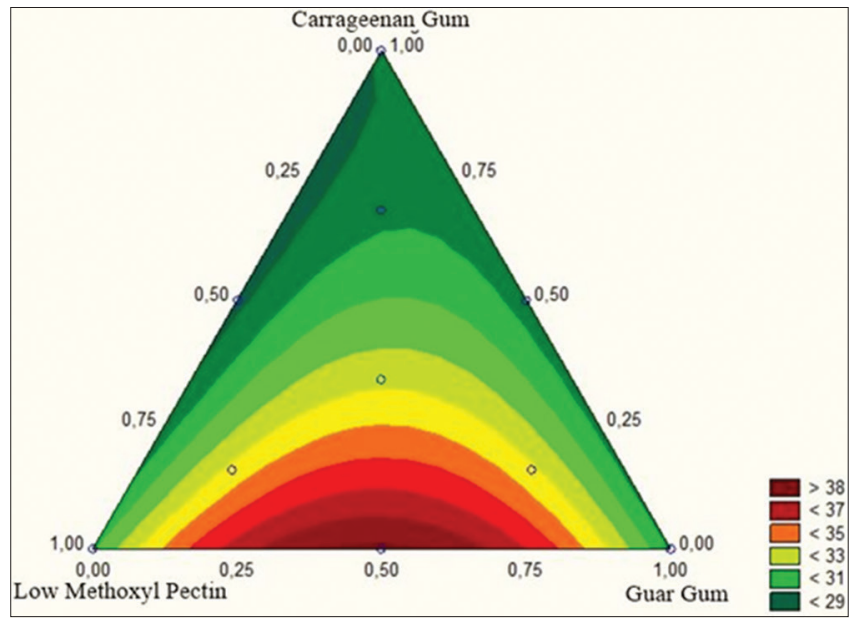

Fig 2. Contour Plot to the Lightness $\left(L^{*}\right)$ of Mixed Low Caloric Orange Jellies. 
exhibited a tendency to darken. Regarding carrageenan, Pietrasik (2003) studied the binding and texture properties of gels in processed meat with carrageenan, egg albumin, and microbial transglutaminase, and they observed that the nonmeat ingredients influenced the color parameters; however, the addition of carrageenan resulted in darker products compared with those without any addition. Additionally, the gel luminosities were affected by the interactive effects of carrageenan and egg albumin with microbial transglutaminase.

The mean values for red/green $\left(\mathrm{a}^{*}\right)$ and blue/yellow (b*) coordinates of the jellies are shown in Table 5. Formulation $4(0.5 \% \mathrm{LMP}$ and $0.5 \%$ guar gum) obtained higher values of $a^{*}$ and $b^{*}$, differing statistically from the other formulations $(p \leq 0.05)$. This means that the combination of LMP and guar gum (1:1) causes the jellies to have a reddish yellow color. In contrast to the results obtained in this study, several authors observed that the addition of LMP or HMP diminishes the intensity of color (parameters $\mathrm{a}^{*}$ and $\mathrm{b}^{*}$ ) of the jellies (Dervisi et al., 2001; Nachtigall et al., 2004).

Moisture values for the formulations varied between $42.49 \%$ and $68.37 \%$ (Table 5). The formulations that presented the highest rates were F1 (1\% LMP), F5 (0.5\% LMP and $0.5 \%$ carrageenan), F6 (0.5\% guar gum and $0.5 \%$ carrageenan), and F9 (0.16\% LMP, $0.16 \%$ guar gum, and $0.68 \%$ carrageenan), therefore indicating the occurrence

\begin{tabular}{|c|c|c|c|}
\hline Formulations & $a^{*}$ & $\mathbf{b}^{*}$ & Moisture (\%) \\
\hline $\mathrm{F} 1$ & $4.01 \pm 0.12 b$ & $9.50 \pm 1.58 c$ & $62.20 \pm 3.02 a$ \\
\hline $\mathrm{F} 2$ & $3.62 \pm 0.07 c$ & $12.12 \pm 0.27 c$ & $59.61 \pm 1.72 b$ \\
\hline F3 & $3.62 \pm 0.08 \mathrm{c}$ & $9.21 \pm 1.73 c$ & $44.04 \pm 6.07 c$ \\
\hline $\mathrm{F} 4$ & $4.84 \pm 0.53 a$ & $21.36 \pm 4.35 a$ & $42.49 \pm 6.84 c$ \\
\hline F5 & $3.66 \pm 0.06 c$ & $11.20 \pm 0.73 c$ & $68.37 \pm 6.10 a$ \\
\hline F6 & $4.21 \pm 0.22 b$ & $10.70 \pm 0.98 c$ & $64.29 \pm 4.05 a$ \\
\hline F7 & $3.22 \pm 0.28 c$ & $13.44 \pm 0.38 c$ & $47.25 \pm 4.47 c$ \\
\hline F8 & $2.63 \pm 0.57 d$ & $9.82 \pm 1.42 \mathrm{c}$ & $56.50 \pm 0.17 b$ \\
\hline F9 & $3.76 \pm 0.01 c$ & $16.88 \pm 2.11 b$ & $61.89 \pm 2.85 a$ \\
\hline $\mathrm{F} 10$ & $4.16 \pm 0.19 b$ & $12.44 \pm 0.11 c$ & $55.13 \pm 0.52 b$ \\
\hline
\end{tabular}

Mean values with common letters in the same column indicate that there is no significant difference among samples $(p \leq 0.05)$ from Scott-Knott's mean test. $F 1,1 \%$ LMP pectin; $F 2,1 \%$ guar gum; $F 3,1 \%$ carrageenan gum; $\mathrm{F} 4,0.5 \% \mathrm{LMP}$ pectin and $0.5 \%$ guar gum; $\mathrm{F} 5,0.5 \% \mathrm{LMP}$ pectin and $0.5 \%$ carrageenan gum; $\mathrm{F} 6,0.5 \%$ guar gum and $0.5 \%$ carrageenan gum; $\mathrm{F} 7,0.68 \% \mathrm{LMP}$ pectin, $0.16 \%$ guar gum and $0.16 \%$ carrageenan gum; $\mathrm{F} 8,0.16 \% \mathrm{LMP}$ pectin, $0.68 \%$ guar gum and $0.16 \%$ carrageenan gum; F9, $0.16 \%$ LMP pectin, $0.16 \%$ guar gum and $0.68 \%$ carrageenan gum; $\mathrm{F} 10,0.33 \%$ LMP pectin, $0.33 \%$ guar gum and $0.34 \%$ carrageenan gum. Formulation 10: mean values obtained by formulations 10, 11 and 12 . of high quantities of water in these formulations. Then, the formulations that presented the lowest rates were F3 (1\% carrageenan), F4 (0.5\% LMP and $0.5 \%$ guar gum), and F7 (0.68\% LMP, $0.16 \%$ guar gum and $0.16 \%$ carrageenan), resulting in jellies with a lower probability of microorganism proliferation once they exhibited less moisture ( $p \geq 0.05)$. According to Santos (2012), moisture is a quality parameter for processed food. Excess moisture promotes the deterioration of the food, directly influencing its conservation. Moreover, according to Damiani et al. (2009), a high level of moisture diminishes the shelf life of jellies, by facilitating fungi and yeast growth.

The variations in moisture of the jellies likely occurred due to the differences in the chemical links that occurred during gel formation, which is influenced by different anions and the ionic ability to connect with the water in the gel due to the presence of calcium and/or sugar (Santos, 2012). The addition of LMP alone resulted in higher moisture values because of the chemical structure of the molecule, which involved a larger number of ramifications; it caused a larger interaction with water molecules and consequently caused an increase in water retention. However, LMP in combination with guar gum resulted in low moisture values, which may be attributed to the tendency toward intermolecular association of those gums.

For the total acidity, there was a significant positive effect $(\mathrm{p} \leq 0.05)$ between isolated hydrocolloids of X1 (LMP), X2 (guar gum), and X3 (carrageenan) (Table 6), and these hydrocolloids affected the parameters in a similar way (similar coefficients). For the total sugar values (Table 6), there was a significant effect $(\mathrm{p} \leq 0.05)$ among X1 (LMP), $\mathrm{X} 2$ (guar gum), and X3 (carrageenan) and between X1 and $\mathrm{X} 2$ (LMP and guar gum), and this interaction between X1 and $\mathrm{X} 2$ produced a higher effect on the total sugar values.

It was observed (Figure 3a) that the jellies that presented the largest acidity values were obtained in regions with LMP concentrations that were higher than $0.75 \%$ because the lowest acidity values were obtained from regions with a combination of from $0.25 \%$ to $0.75 \%$ of guar gum and from $0.25 \%$ to $0.75 \%$ of carrageenan. Therefore, addition of high concentrations of LMP made the jellies more acidic. The chemical structure of pectin includes a main linear chain of repeated units of D-galacturonic acid linked to $\alpha-(1,4)$ links, where the carboxylic groups may be methyl esterified in different extensions (Yapo and Koffi,

Table 6: Predicted model of total acidity and total sugar of mixed low caloric orange Jellies

\begin{tabular}{lrr}
\hline Parameter & Predicted model & $\mathbf{R}^{2}$ \\
\hline Total acidity (g citric acidy/100 g) & $0.45 \mathrm{X}_{1}{ }^{*}+0.41 \mathrm{X}_{2}{ }^{*}+0.40 \mathrm{X}_{3}{ }^{*}-0.21 \mathrm{X}_{1} \mathrm{X}_{2}-0.10 \mathrm{X}_{1} \mathrm{X}_{3}-0.18 \mathrm{X}_{2} \mathrm{X}_{3}$ & 0.71 \\
Total sugars (\%) & $8.68 \mathrm{X}_{1}{ }^{*}+11.96 \mathrm{X}_{2}{ }^{*}+9.03 \mathrm{X}_{3}{ }^{*}+22.45 \mathrm{X}_{1} \mathrm{X}_{2}{ }^{*}-14.02 \mathrm{X}_{1} \mathrm{X}_{3}-14.26 \mathrm{X}_{2} \mathrm{X}_{3}$ & 0.78 \\
\hline
\end{tabular}

$\mathrm{X}_{1}$ : low methoxyl pectin (LMP), $\mathrm{X}_{2}$ : guar gum, $\mathrm{X}_{3}$ : carrageenan gum. ${ }^{* \star}$ Significance to level of 0.05 . 
2006; Yapo et al., 2007). At temperatures above $10^{\circ} \mathrm{C}$ in an acidic environment, the mechanism of depolymerization (decrease in the size of the polymeric chain) occurs via hydrolysis (acid or enzymatic) of the $\alpha(1-4)$ link-releasing units of galacturonic acids (Canteri et al. 2012). During the processing of the orange jelly formulations, with a high LMP concentration (above $0.75 \%$ ), the ingredients were exposed to temperatures above $10^{\circ} \mathrm{C}$; consequently, the high temperature contributed to the degradation of pectin,

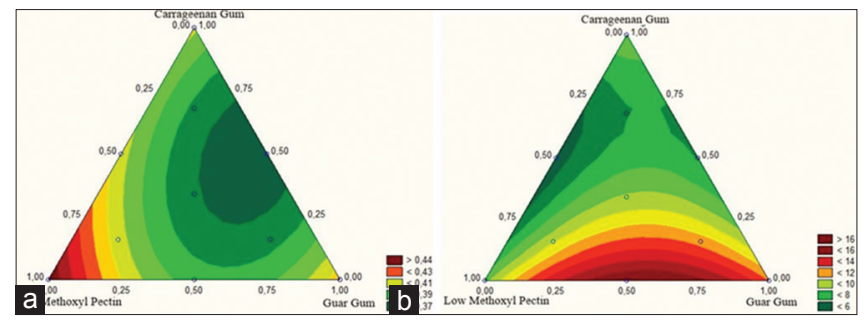

Fig 3. Contour Plot to the Total Acidity (a) and Total Sugar (b) of Mixed Low Caloric Orange Jellies. causing a break in the $\alpha(1-4)$ links and releasing galacturonic acid and therefore increasing the acidity of the jellies.

Regarding the total sugars values, higher concentrations in the formulations between $0.25 \%$ and $1 \%$ for guar gum and between $0.25 \%$ and $0.75 \%$ for LMP (Figure $3 \mathrm{~b}$ ) were observed. Then, the lowest values were between $0.25 \%$ and $1 \%$ for carrageenan, below $0.25 \%$ for LMP, and between 0 and $0.25 \%$ for guar gum, demonstrating that the use of gelling agents influenced the total sugar values. The combination of LMP and guar gum tended to increase the total sugar values. Some sugars, such as galactose, glucose, rhamnose, arabinose, and xylose, are also present in the pectin structures with typically between $5 \%$ and $10 \%$ (in mass) of galacturonic acid inserted as side chains or as isolated contaminants (Yapo and Koffi, 2006; Yapo et al., 2007). At high temperatures, depolymerization of LMP by hydrolysis of the $\alpha(1-4)$ - releasing links occurs; therefore, galacturonic acid units are released (Canteri et al., 2012).

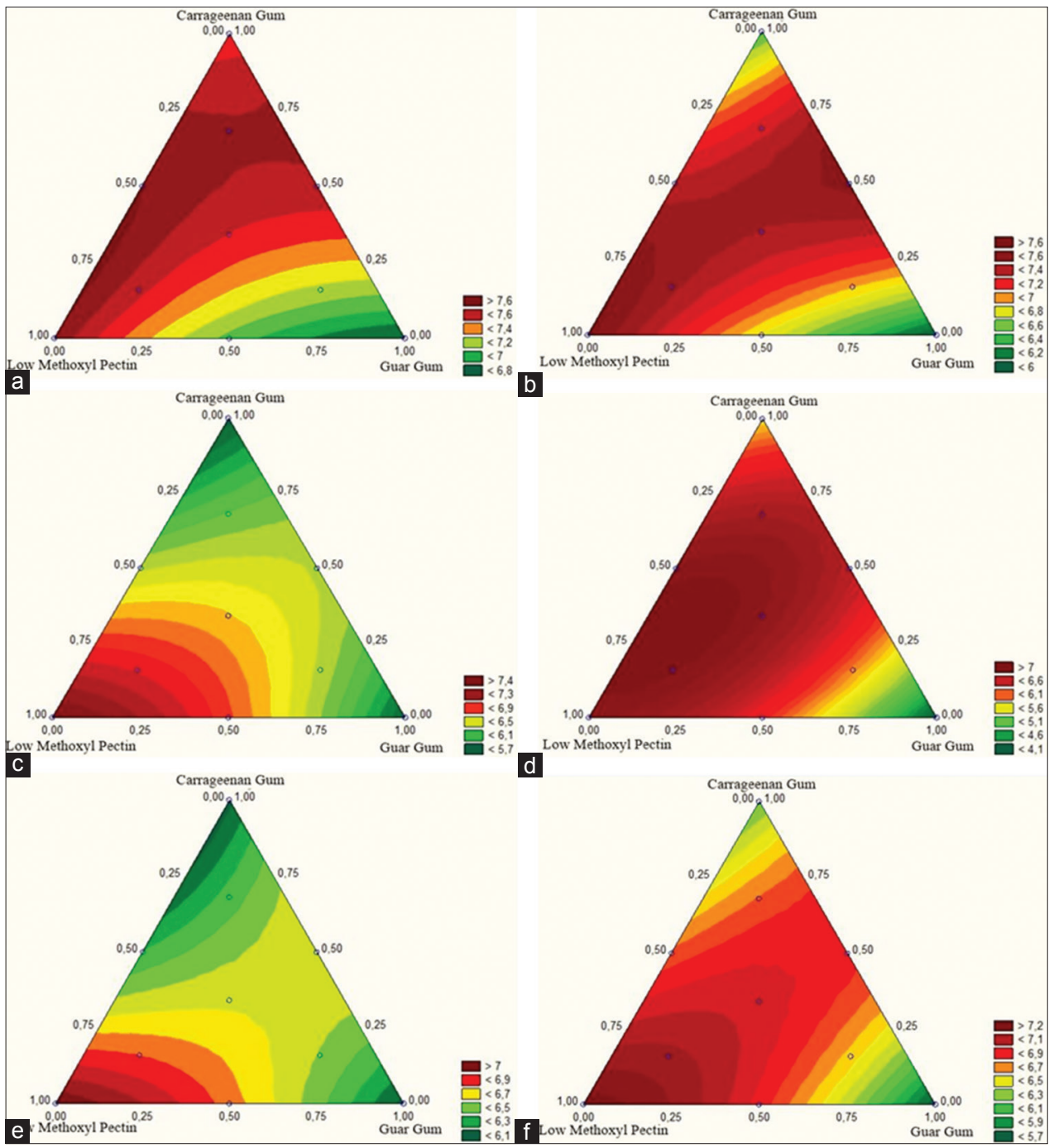

Fig 4. Contour Plot to the Sensory Attributes: Color (a), Appearance (b), Flavor (c), Consistency (d), Sweetness (e) and Overall Liking (f) of Mixed Low Caloric Orange Jellie. 
According to Mudgil et al. (2014), guar gum is a glycosidic polysaccharide constituted with units of $\beta-1,4$ glycosidic mannose and includes a $\alpha-1,6$ galactose unit in every two units of mannose, causing ramifications. In the present study, the increase in the total sugars in the orange jellies by the use of the combination LMP/guar gum likely occurred as a consequence of degradation of these gelling agents due to high temperature, therefore, the hydrolysis of the LMP molecule and the guar gum, which provokes the release of sugars from the molecule, increases the total sugar value of the jelly.

\section{Sensory evaluation}

In general, for all attributes assessed, the highest scores were obtained in regions above $0.75 \%$ LMP (Figure 4). The lowest scores were obtained in regions with more than $0.75 \%$ guar gum.

Regarding the color attribute (Figure 4a), it has been reported in the literature that the addition of LMP or HMP decreases the intensity of color (parameters $a^{*}$ and $b^{*}$ ) of jellies (Dervisi et al., 2001; Nachtigall et al., 2004). Nevertheless, in this study, the negative influence of LMP on the formulation colors regarding the acceptability was not verified.

For the appearance attribute (Figure 4b), the lowest scores for jellies with high guar gum concentrations were obtained because guar gum produces viscous solutions and is used in applications in which thickening, stabilization, rheological and viscosity control, suspension and formation of the body, modification of the texture, and retention of water are required; however, it does not form gels (Dziezak, 1991; Sanderson, 1996). Probably, the lower scores obtained for concentrations of approximately $1 \%$ were due to the nonformation of gels.

For the flavor attribute (Figure 4c), in the study by Kostyra and Baryłko-Pikielna (2007) on the effect of fat levels and the addition of guar gum in emulsions, such as mayonnaise, on the sensory perception of flavor, the authors observed that the addition of guar gum decreased the perception of flavor in the product. These authors reported that this result is associated with the structure of the guar gum, which forms a high viscosity system. In the study by Pereira (2012) on the effect of additives on the rheological and sensory properties of sugar-free guava preserves, the effects of three gelling agents (locust bean gum, carrageenan and LMP) were evaluated, and it was verified that an increase in the addition of carrageenan resulted in lower scores for the flavor attribute. According to Bayarri et al. (2004) and Bayarri et al. (2006), the concentration of gelling agents modifies the mechanical properties (diffusion) of gels, influencing the perception of flavor, corroborating with the results obtained in this study. In a study on sweet aromatized gels prepared with alginate, carrageenan, or agar, Chai et al. (1991) observed that the sensory perceptions depend not only on the force of the gel but also on the concentration of the gelling agent.

Regarding the attribute of consistency (Figure 4d), possibly, the low acceptability related to guar gum occurred because of the characteristic of not forming a gel (Nikaedo et al., 2004).

Regarding the sweetness attribute (Figure 4e), as previously stated, LMP can undergo degradation at elevated temperature and thus release sugars, making the product sweeter.

\section{CONCLUSION}

For the rheological and colorimetric characteristics of the jellies, formulations with high LMP concentration increased the flow index and consistency index, resulting in low caloric orange jellies with a texture that was rigid structure and light color. Regarding the acidity, the jellies with LMP concentration above $0.75 \%$ were more acidic. The jelly formulations with carrageenan concentration above $0.25 \%$ had lower total sugar values. Regarding acceptability, the formulations added only with LMP presented the best results. Also, the formulations containing high guar gum concentration obtained less acceptance. Therefore, it is concluded that for the preparation of low caloric orange jellies, it is necessary to use LMP concentration between $0.75 \%$ and $1 \%$, carrageenan concentration of $0 \%-0.25 \%$ and to exclude guar gum.

\section{ACKNOWLEDGMENTS}

The authors thank FAPEMIG (APQ 02047-14) for financial support, and the authors are grateful for the donation of sweeteners from Nutramax ${ }^{\circledR}$.

\section{Authors' contributions}

Michelle Barbosa Lima, Flávia Mappa Domingos and Jerusa Josiane Francisca de Jesus Lima conducted the experiments and collected the data; Reginaldo de Souza Monteiro and Orlando David Henrique dos Santos performed the rheological measurements; Patrícia Aparecida Pimenta Pereira was involved in manuscript preparation and supervised the research project.

\section{REFERENCES}

Acosta, O., F. Víquez and E. Cubero. 2008. Optimisation of low calorie mixed fruit jelly by response surface methodology. Food 
Qual. Prefer. 19: 79-85.

AOAC. 2005. Official Methods of Analysis of AOAC International, $18^{\text {th }}$ ed. AOAC International, Arlington, Virginia, USA.

Arda, E., S. Kara and Ö. Pekcan. 2009. Synergistic effect of the locust bean gum on the termal phase transitions of k-carragena gels. Food Hydrocoll. 23: 451-459.

Bayarri, S., L. Duran and E. Costell. 2004. Influence of sweeteners on the viscoelasticity of hydrocolloids gelled systems. Food Hydrocoll. 18: 611-619.

Bayarri, S., L. Izquierdo, L. Durán and E. Costell. 2006. Effect of addition of sucrose and aspartame on the compression resistance of hydrocolloids gels. Int. J. Food Sci. Technol. 41: 980-986.

Campos, A. M. and L. M. B. Cândido. 1995. Formulação e avaliação físico-química e reológica de geléias de baixo teor de sólidos solúveis com diferentes adoçantes e edulcorantes. Ciên. Tecnol. Alimentos. 15: 268-278.

Canteri, M. H. G., L. Moreno, G. Wosiacki and A. P. Scheer. 2012. Pectin: From raw material to the final product. Polímeros. 22: 149-157.

Chai, E., D. G. Oakenfull, R. L. Mcbride and A. G. Lane. 1991. Sensory perception and rheology of flavoured gels. Food Aust. 43: 256-261.

Chow, C. K. 2000. Fatty Acids in Foods and their Health Implications. $2^{\text {nd }}$ ed. Marcel Dekkler, Inc., USA, p. 1045.

Cui, S. W. 2005. Food Carbohydrates: Chemistry, Physical Properties, and Applications. CRC Press, Boca Raton, Flórida.

Damiani, C., E. V. B. Boas, M. S. Jr. Soares, M. Caliari, M. L. Paula and E. R. Asquieri. 2009. Chemical evaluation of mango (Mangifera indica L) jams formulated with different levels of peels in substitution to pulp. Ciên. Agrotecnol. 33: 177-184.

Dervisi, P., J. Lamb and I. Zabetakis. 2001. High pressure processing in jam manufacture: Effects on textural and colour properties. Food Chem. 73: 85-91.

Dische, Z. 1962. General color reactions. In: Whistler, R. L. and M. L. Wolfran (Ed.), Carbohydrate Chemistry. Academic, New York, pp. 477-512.

Dunstan, D. E., Y. Chen, M. L. Liao, R. Salvatore, D. V. Boger and M. Prica. 2001. Structure and rheology of the k-carrageenan/ locust bean gum gels. Food Hydrocoll. 15: 475-484.

Dziezak, J. D. 1991. A focus on gums. Food Technol. 45: 116-132.

Fennema, O. R., S. Damodaran and K. L. Parkin. 2010. Química de Alimentos de Fennema. Editora Artmed, Porto Alegre.

Ferreira, D. F. 2000. Programa Sisvar: Versão 3,04. UFLA/DEX, Lavras.

Ferreira, R. M. A., E. M. M. Aroucha, A. V. Góis, K. D. Silva and C. M. G. Sousa. 2011. Sensorial quality of mixed jelly of watermelon and tamarind. Rev. Caatinga. 24: 202-206.

Gajar, A. M. and N. Badrie. 2001. Processing and quality evaluation of a low-calorie christophene jam (Sechium edule (Jacq.) swartz. J. Food Sci. 67: 341-345.

Hoffman, L. C. 2008. The yield and nutritional value of meat from African ungulates, camelidae, rodents, ratites and reptiles. Meat Sci. 80: 94-100.

Holdsworth, S. D. 1971. Applicability of rheological models to the interpretation of flow and processing behavior of fluid food products. J. Texture Stud. 2: 393-418.

IAL. 2008. Normas Analíticas do Instituto Adolfo Lutz. IAL, São Paulo.

Jayaprakasha, G. K., B. Girennavar and B. S. Patil. 2008. Antioxidant capacity of pummelo and navel oranges: Extraction efficiency of solvents in sequence. LWT Food Sci. Technol. 41: 376-384.
Kostyra, E. and N. Baryłko-Pikielna. 2007. The effect of fat levels and guar gum addition in mayonnaise-type emulsions on the sensory perception of smoke-curing flavour and salty taste. Food Qual. Prefer. 18: 872-879.

Lau, M. H., J. Tang and B. G. Swanson. 2000. Kinetics of textural and colour changes in green asparagus during thermal treatments. J. Food Eng. 45: 231-236.

Mandala, I. G., T. P. Savvas and A. E. Kostaropoulos. 2004. Xanthan and locust bean gum influence on the rheology and structure of a white model-sauce. J. Food Eng. 64: 335-342.

Mudgil, D., S. Barak and B. S. Khatkar. 2014. Process optimization of enzymatic hydrolysis of guar gum using response surface methodology. J. Food Sci. Technol. 51: 1600-1605.

Nachtigall, A. M., E. L. Souza, M. B. Malgarim and R. C. Zambiazi. 2004. Blackberry light jellies. Bol. Cent. Pesqui. Processamento Alimentos. 22: 337-353.

Nikaedo, P. H. L., F. F. Amaral and A. L. B. Penna. 2004. Technological characterization of creamy chocolate dairy desserts prepared with whey protein concentrate and a mixture of carrageenan and guar gum. Braz. J. Pharm. Sci. 40: 397-404.

Oliveira, C. F. D., E. G. Pinto, A. C. Tomé, R. C. Quintana and B. F. Dias. 2016. Development and characterization of jelly orange enriched with oats. Rev. Agric. Neotrop. 3: 20-23.

Oliveira, E. N. A., A. P. T. Rocha, J. P. Gomes and D. C. Santos. 2014. Processing and physicochemical characterization of diet umbucajá (Spondias Spp.) Jellies. Biosci. J. 30: 1007-1016.

Pereira, P. A. P. 2012. Effects of Additives on the Rheological and Sensorial Properties of Sugar-Free Guava Preserves. (Doctoral Dissertation). Federal University of Lavras, Lavras.

Pereira, P. A. P., V. R. Souza, M. A. Vieira, F. Queiroz, S. V. Borges and J. D. S. Carneiro. 2017. Sugar-free guava preserve: Influence of additives on textural properties. Int. Food Res. J. 24: 2377-2386.

Pietrasik, Z. 2003. Binding and textural properties of beef gels processed with k-carrageenan, egg albumin and microbial transglutaminase. Meat Sci. 63: 317-324.

Ramírez, J. A., M. Barrera, O. G. Morales and M. Vásquez. 2002. Effect of xanthan and locust bean gums on the gelling properties of myofibrillar protein. Food Hydrocoll. 16: 11-16.

Rhein-Knudsen, N., M. Ale and A. Meyer. 2015. Seaweed hydrocolloid production: An update on enzyme assisted extraction and modification technologies. Mar. Drugs. 13: 3340-3359.

Sanderson, G. R. 1996. Gums and their use in food systems. Food Technol. 50: 81-84.

Santos, C. O. 2012. Industrial Use of "Honey" of Cocoa (Theobroma cacao L.) in the Production of Sugar-Free Jelly. (Masters Dissertation). Federal University of Bahia, Salvador.

Souza, V. R., P. A. P. Pereira, A. C. M. Pinheiro, C. A. Nunes, T. L. T. Silva, S. V. Borges and F. Queiroz. 2012. Multivariate approaches for optimization of the acceptance: Optimization of a Brazilian cerrado fruit jam using mixture design and parallel factor analysis. J. Sens. Stud. 27: 417-424.

Steffe, J. F. 1996. Rheological Methods in Food Process Engineering. Freeman Press, Michigan.

Stone, H. S. and J. Sidel. 1993. Sensory Evaluation Practices. Academic Press, San Diego, Calif.

Tavassoli-Kafrani, E., H. Shekarchizadeh and M. MasoudpourBehabadi. 2016. Development of edible films and coatings from alginates and carrageenans. Carbohydr. Polym. 137: 360-374.

USDA. 2005. Departament of Agriculture, Agricultural Research Service. Nutrient Database for Standard Reference, United States.

Yapo, B. M. and K. L. Koffi. 2006. Yellow passion fruit rind-a potential 
Lima, et al.

source of low-methoxyl pectin. J. Agric. Food Chem. 54: 27382744.

Yapo, B. M., C. Robert, L. Etienne, B. Wathelet and M. Paquot. 2007. Effect of extraction conditions on the yield, purity and surface properties of sugar beet pulp pectin extracts. Food Chem. 100: 1356-1364.
Yasar, F., H. Togrul and N. Arslan. 2007. Flow proprerties of celulose and carboxymethyl celulose from orange peel. J. Food Eng. 81: 187-199.

Zambiazi, R. C., J. F. Chim and M. Bruscatto. 2006. Avaliação das características e estabilidade de geléias light de morango. Alimentos Nutrição. 17: 165-170. 